\title{
(RE)PENSANDO A LEITURA NA EDUCAÇÃO DE JOVENS E ADULTOS: POR UMA PRÁTICA LETRADA
}

\author{
Itana Sousa da Silva* \\ Lucas Santos Campos
}

RESUMO: Este trabalho tem como objetivo discutir o processo de leitura na Educação de Jovens e Adultos (pós-alfabetização) buscando compreender o que é ler, quais os focos dessa prática e sua relevância para o público da Educação de Jovens e Adultos (EJA). Refletimos sobre a necessidade de ressignificação do conceito de leitura com o intuito de ampliarmos nossas concepções e (re)pensarmos nossas práticas cotidianas em sala de aula possibilitando a formação de leitores para uma prática letrada que os tornem capazes de interagir usando a linguagem de diferentes maneiras em diferentes ações e em diferentes grupos, sejam eles sociais, culturais etc. Realizamos um breve histórico da EJA nos apoiando nos estudos de Arroyo (2005); tomamos por base os conceitos de leitura trazidos por Arroyo (2005), Kleiman (1999, 2013), Silva (1999, 2002), Soares (2003) e pelos Parâmetros Curriculares Nacionais (PCN) (1998); e por fim, nos apoiamos em Kleiman (1998, 2005), Silva 1999), Soares (1998), e Rojo (2009) para tratar do letramento. Mantendo como proposta (re)pensar a leitura nas turmas de Educação de Jovens e Adultos percebemos que o processo de formação de leitores nesta modalidade de ensino será mais prazerosa e significativa e, consequentemente, obterá melhores resultados se forem levados em consideração os contextos sócio-históricos em que estes sujeitos estão inseridos.

PALAVRAS-CHAVE: EJA; Leitura; Letramento.

\section{Introdução}

Com objetivo discutir o processo de leitura na Educação de Jovens e Adultos (pósalfabetização) este artigo propõe uma reflexão acerca da necessidade de ressignificação do conceito de leitura no intuito de ampliarmos nossas concepções e (re)pensarmos nossas práticas cotidianas em sala de aula para esta modalidade, visto que, a maioria das práticas escolares não levam em conta o espaço e o tempo transcorridos e a historicidade dos sujeitos, presumem a existência de um sujeito independentemente do tempo e do espaço,

\footnotetext{
* Mestranda do Programa de Pós-Graduação Stricto Sensu em Letras: Cultura, Educação e Linguagem pela Universidade Estadual do Sudoeste da Bahia (Uesb).

** Doutor em Letras pela Universidade Federal da Bahia (Ufba). Professor Pleno da Universidade Estadual do Sudoeste da Bahia (Uesb). Realizou estágio pós-doutoral na Universidade Federal do Rio de Janeiro (UFRJ). 
reafirmando modelos antigos que se prendem aos procedimentos de leitura levando em consideração apenas o código escrito no papel. Mesmo nessa conjectura existe um forte discurso em transformar alunos em leitores experientes, incentivando o hábito de leitura na escola. Neste ponto, nos apegaremos para discutir sobre o que é ler, quais são os focos/objetivos dessa leitura "ensinada" na escola e sua relevância para os alunos da EJA, posto que, as práticas de leitura e escrita no âmbito escolar não podem ser desvinculadas dos contextos sócio-históricos desses alunos devido ao grande número de usos e funções da escrita para as interações sociais.

O público da Educação de Jovens e Adultos é constituído por pessoas que ficaram fora da escola por algum tempo ou por muito tempo por diversos motivos, sejam eles sociais, econômicos, políticos. Alunos que ainda vivenciam a exclusão por não ter o conhecimento da leitura a seu favor, mesmo sendo sujeitos capazes de inserção e interação social. Assim, a leitura nas turmas de EJA não pode ser limitada apenas do ponto de vista pedagógico, pois a leitura requer condições que permitam formar seres sociais, éticos, políticos, dentre outros, sem que se leve em conta apenas o código escrito. O aprendizado precisa deixar de ser uma mera transmissão de conhecimentos do professor ao aluno e a escola precisa criar condições para uma nova leitura, permitindo ao aluno compreender e participar das mais diversas manifestações culturais e perceber a leitura e a escrita de forma reflexiva e crítica.

A partir dessa premissa surge a ideia de letramento que oferece de maneira bastante eficaz um conceito que vincula atividades de leitura e escrita envolvendo valores, atitudes e relações sociais, como assinala Soares (1998),

Ser letrado é informar-se através da leitura, é buscar informações nos jornais, revistas e livros e fazer uso delas. É assistir à televisão e selecionar o que desperta interesse. É seguir instruções, usar a leitura como apoio de memória ou para comunicação. É ler histórias que nos levam a lugares desconhecidos, é emocionar-se com elas. É usar a escrita para se orientar no mundo para não ficar perdido. É escrever um bilhete ou uma lista de compras. É descobrir a si mesmo, através do envolvimento com a leitura e com a escrita nas diferentes práticas sociais. 
Corroborando com o autor supracitado Rojo (2009) argumenta que as pessoas se utilizam da leitura e escrita no seu dia a dia e mesmo assim são consideradas analfabetas por não terem um "bom" nível de escolaridade, mas conseguem ir ao banco fazer saques e depósitos, consultar agenda telefônica, tomar uma condução, ver telejornal, ver novelas, bater papo em redes sociais, dentre tantas outras atividades.

Em síntese, esta modalidade de ensino requer que jovens e adultos sejam, antes de tudo, compreendidos como sujeitos e agentes sociais protagonistas na construção de práticas e conhecimentos significativos, sujeitos com características próprias que precisam ser respeitadas e entendidas como recursos pedagógicos nas práticas de leitura e escrita exercidas no contexto escolar.

\section{Resumo histórico da EJA}

O marco inicial das políticas para a educação de jovens e adultos emergiu desde a colonização portuguesa, no século XVI com a Companhia de Jesus que visava por meio da alfabetização catequizar o índio adulto, à cristianização e à aculturação. Ao longo da história do Brasil, vencido o ciclo econômico colonialista, a educação de adultos é abandonada, pois era desnecessária ao português pobre ou a seu escravo negro.

No século XIX, mais precisamente, no período de 1860 a 1876, surgem 117 escolas noturnas, acompanhando o desenvolvimento da Escola Elementar com base nas ideias de progresso, crescimento econômico e mutações na sociedade. No entanto, o movimento foi considerado irregular e não obteve expansão.

Após a Proclamação da República, em 1889, acontece a reforma do Ensino Elementar agora com princípios republicanos e a Educação de Adultos passa a ser tratada enquanto parte da Educação Popular, sem mais interesses sociais por parte das oligarquias.

No Final do século XIX início do século XX, surge a educação anarquista de princípios revolucionários com bases libertárias contra a opressão e a coerção. Esforços no sentido de uma Educação Popular que propunha via a alfabetização, atividades culturais, palestras, etc., buscavam despertar para a autogestão, a autoeducação como mecanismos de se opor às diferentes formas de opressão. Entretanto, discórdias internas ao movimento, 
tendências marxista e comunista dentro do próprio movimento operário e a repressão externa inviabilizam a expansão da tendência no Brasil.

Na década de 20 do século XX, fase bastante confusa, com a coexistência de princípios tecnicistas, modernistas e socialistas, surgem os "Cursos Populares Noturnos", que conferiam, em 2 anos, o título de Ensino Técnico Elementar a adultos analfabetos, que estudavam cultura geral e formação em higiene, por meio de projeções, palestras e demonstrações práticas. Esse processo é interrompido na Revolução de 30.

No início do governo Vargas em 1931, é assinado um convênio estatístico que inclui a categoria Ensino Supletivo com intencionalidade política liberal e doutrinária da Escola Nova. Nesse contexto, o Manifesto dos Pioneiros da Educação, liderado por Anísio Teixeira, Fernando de Azevedo, Lourenço Filho e Cecília Meireles, é assinado por 27 educadores, em favor de um Plano Nacional de Educação.

O Decreto n 3.763 de $1^{\circ}$ de fevereiro 1932 determinou a criação dos Cursos de Continuação e Aperfeiçoamento/CCA para estabelecimentos de Ensino Profissional e o Decreto 4.299 promoveu a Reforma do Ensino Elementar de Adultos e organiza os CCA, que foi entregue a Paschoal Leme (progressista antiliberal), que acabou preso por difundir ideias marxistas aos operários. Não houve implantação deste decreto por falta de recursos e mais uma vez a educação para jovens e adultos foi colocada em segundo plano. Em novembro de 1935, com o Levante Comunista, os cursos são todos interrompidos e Anísio Teixeira e seus colaboradores são afastados da Educação até o final do Estado Novo (1945), o que significou a breve existência da EJA com características próprias no Brasil. Salientando que, de 1932 a 1935 o Ensino Supletivo chegou a ter 120.826 matrículas com 1.666 escolas.

A partir de 1943 reiniciam-se as mobilizações em prol da educação de adultos. As esquerdas organizam os Comitês Democráticos, surgiram as Universidades Populares/UP e os Centros de Cultura Popular. Em 1947 os Comitês foram extintos e algumas Universidades também.

Em 1948, Clemente Mariani envia um Projeto de Lei para a primeira LDB (só aprovada em 1961). Nesta época, surgem dois grandes processos: o Movimento em Defesa da 
Escola Pública e o Movimento por uma Educação Popular, este último é predominantemente no setor da Educação Informal e na Educação de Adultos.

A Lei 5.379/67 - Cria uma Fundação denominada Movimento Brasileiro de Alfabetização (MOBRAL), com o objetivo de erradicar o analfabetismo e propiciar a educação continuada de adolescentes e adultos.

Na Lei 5.692/71, o Ensino Supletivo ganhou capítulo próprio com cinco artigos. Um deles dizia que este ensino se destinava a "suprir a escolarização regular para adolescentes e adultos, que não tinham seguido ou concluído na idade própria”. Com uma visão bastante sistêmica de suplência, suprimento, aprendizagem e qualificação, o Ensino Supletivo era concebido para os $1^{\circ}$ e $2^{\circ}$ Graus.

Bastante desacreditado, o MOBRAL foi extinto no governo José Sarney. Surge a Fundação Educar, com a função de apoiar financeira e tecnicamente iniciativas de governos, entidades civis e empresas, comprometidas com a Educação de Adultos, trazendo à tona uma "Pedagogia Libertadora".

Em meados dos anos 80 com Jean Piaget e Emília Ferreiro, as ideias de Construtivismo e da Psicolinguística, a Educação de Adultos entra numa fase de tratamento científico pedagógico, por parte dos profissionais da Educação, o que repercute sobre a produção de recursos de ensino, construção de Planos Curriculares, política de formação de educadores. A partir da V Conferência Internacional sobre Educação de Adultos CONFINTEA, realizada em Hamburgo, na Alemanha, de 14 a 18 de julho de 1997, resultaram a Declaração de Hamburgo e a Agenda para o Futuro da Educação de Adultos (Concepção político educacional da UNESCO), define sobre a importância da EJA, tanto para países desenvolvidos, quanto para os em desenvolvimento, enquanto mecanismos de sobrevivência nas sociedades da informação e do conhecimento.

A Constituição Nacional de 1988 estabelece a obrigatoriedade de ofertas educacionais a jovens e adultos excluídos de sua escolarização, tanto pelos problemas sócio-econômico-culturais quanto pela excludência gerada pela cultura escolar brasileira. E estabelece um prazo de 10 anos para que toda a sociedade civil erradique o analfabetismo, o que não aconteceu. 
A Lei 9394/96 define que a Educação de Jovens e Adultos (que se refere aos que foram excluídos de oportunidades educacionais apropriadas) deve ser garantida a todos gratuitamente, distinguindo-a da Educação Profissional, destinada ao aprimoramento e a qualificação dos que estão vinculados a vida produtiva. No Brasil, o principal documento que orienta as ações sobre a EJA é o Parecer CNE/CEB 11/2000 do Conselho Nacional de Educação e Câmara de Educação Básica, o qual apresenta as DCN - Diretrizes Curriculares Nacionais para a Educação de Jovens e Adultos.

A partir desse histórico, percebe-se que a EJA tem e sempre teve em seu contexto indivíduos pertencentes a classes dos excluídos, fazendo-se necessário uma "educação libertadora"1, que humanize os sujeitos, não se pautando somente na leitura para decodificação, pois esses educandos trazem uma bagagem de conhecimentos de outras instâncias sociais, que são muito significativas e devem ser consideradas na elaboração do currículo escolar, o qual precisa ter uma metodologia diferenciada porque apresenta características distintas do ensino regular, embora, diante de todo histórico apresentado, seja perceptível o descaso, por parte dos poderes públicos, com esta modalidade de ensino que só a pouco tempo passou a ser reconhecida e normatizada.

Segundo Arroyo (2005, p.5), “A EJA tem como sujeitos as camadas rurais, os camponeses excluídos da terra e as camadas urbanas marginalizadas, excluídas dos espaços, dos bens das cidades". Esses sujeitos são frutos de uma realidade que não deu conta de reparar, a gama de indivíduos que não acompanharam o processo de escolarização e consequentemente da leitura, por isso, torna-se pertinente uma abordagem em que a leitura seja direcionada para essa classe e contemple nas suas reflexões a valorização das experiências de vida, seus saberes conquistados ao longo dos tempos, enfim, uma leitura que consiga acompanhar todas as dimensões histórico-sociais do mundo, levando o sujeito a se inserir neste processo e interagir com mais autonomia.

${ }^{1}$ Paulo Freire desenvolveu um trabalho pedagógico que vislumbra a Educação como um ato libertador, através do qual as pessoas seriam agentes que operam e transformam o mundo. 


\section{Em busca de uma conceituação para leitura}

A aprendizagem do código escrito é importante para o desenvolvimento das práticas de leitura e de escrita no cotidiano. No entanto, pode-se aprender a ler e a escrever a partir das práticas sociais, como proposto nos novos Parâmetros Curriculares Nacionais. Nesse sentido, ler e escrever devem ser práticas de letramento presentes no cotidiano escolar, desenvolvidas através de um processo contínuo dos usos sociais e culturais da leitura e da escrita. Nesse aspecto, Silva (2002) diz que a concepção de leitura deve ser levada para um conceito mais completo, uma forma de leitura em que o indivíduo precisa exercitar-se e trazer para as práticas sociais, uma leitura crítica, em que o sujeito possa estar no mundo e intervir nesse mundo de forma pensada e ressignificada, articulada a criticidade obtida através do ato da leitura, "Assim, este tipo de leitura é muito mais do que um simples processo de apropriação de significado; a leitura crítica deve ser caracterizada como um PROJETO, pois concretiza-se numa proposta pensada pelo ser-no-mundo, dirigido ao outro". SILVA (2002, p. 81).

O exercício da leitura deve estar presente em todo processo socioeducativo complementando-o, visto que a leitura é algo de suma importância para a formação do indivíduo. Desta forma, o processo de leitura na EJA se configura em novas ideias, novas visões, novas metodologias, porque a leitura para esta modalidade de ensino precisa ser entendida como algo mais abrangente, algo para além da leitura mecânica, para além da decodificação, além da leitura pela leitura. Ainda de acordo com os PNC (1998, p.70) o professor deve preocupar-se com a diversidade das práticas de recepção dos textos: "não se lê uma notícia da mesma forma que se consulta um dicionário; não se lê um romance da mesma forma que se estuda". Todavia, a leitura aqui propriamente dita é aquela que consegue provocar um novo olhar, provocar uma nova forma de ver o que já foi visto e formular uma nova concepção. Para Arroyo, (2005, p. 35),

Partir dos saberes, conhecimentos, interrogações e significados que aprenderam em suas trajetórias de vida será um ponto de partida para uma pedagogia que se paute pelo diálogo entre os saberes escolares e sociais. Esse diálogo exigirá um trato sistemático desses saberes e significados, alargando-os e propiciando o acesso aos 
saberes, conhecimentos, significados e a cultura acumulados pela sociedade.

Nessa perspectiva, ler é uma prática social que se interliga a outros textos e outras leituras, ou seja, a leitura de um texto pressupõe em ações conjuntas de valores, crenças e atitudes que refletem o grupo social em que as pessoas estão inseridas. A leitura não é apenas o entendimento de um leitor inserido na cultura letrada, mas uma relação de aspectos sociais e culturais que perpassam pela atividade intelectual em que o leitor utiliza diversas estratégias baseadas em seu conhecimento linguístico, sociocultural e enciclopédico (KLEIMAN, 2013, p.16, 17).

Trazendo na íntegra as palavras de Silva (2002, p. 64):

A leitura (ou a resultante do ato de se atribuir um significado ao discurso escrito) passa a ser, então uma via de acesso à participação do homem nas sociedades letradas na medida em que permite a entrada e a participação no mundo da escrita; a experiência dos produtos culturais que fazem parte desse mundo só é possível pela existência de leitores.

Nesse sentido, a prática da leitura é tida como processo que permite ao sujeito compreender a sua razão de ser no mundo, buscando, incessantemente, mais conhecimentos sobre a realidade (SILVA, 1999). Dentro deste contexto, leitores experientes não são aqueles que leem rapidamente, sem movimentar lábios, perceptivelmente e sem subvocalização, não apenas decifrando códigos, mas conhecendo as funções sociais dos textos (KLEIMAN, 1999).

É preciso que nos demos conta de que as necessidades de aprendizagens mudaram, com influência das novas tecnologias, do modelo social e econômico vigente, pelo acesso à informação nas mais diversas mídias. Dessa maneira, os professores da EJA precisam garantir aos educandos um processo que ultrapasse a visão de apenas ensinar a ler e escrever, ou seja, um ensino de leitura que agregue as duas dimensões do letramento: a individual, que se refere à alfabetização, e a sociocultural que envolve o uso e práticas de leitura e escrita (SOARES, 2003), para que o sujeito não regrida do seu processo de aprendizado. 


\section{Sobre o Letramento}

Paulo Freire utilizou o termo alfabetização com um sentido bem próximo do que chamamos hoje de letramento, para designar uma prática sociocultural de uso da língua escrita que foi se transformando ao longo do tempo.

Para Soares (1998),

Ser letrado é informar-se através da leitura, é buscar informações nos jornais, revistas e livros e fazer uso delas. É assistir à televisão e selecionar o que desperta interesse. É seguir instruções, usar a leitura como apoio de memória ou para comunicação. É ler histórias que nos levam a lugares desconhecidos, é emocionar-se com elas. É usar a escrita para se orientar no mundo para não ficar perdido. É escrever um bilhete ou uma lista de compras. É descobrir a si mesmo, através do envolvimento com a leitura e com a escrita nas diferentes práticas sociais.

Acrescentando a ideia de Rojo (2009, p.75),

Ler envolve diversos procedimentos e capacidades (perceptuais, motoras, cognitivas, afetivas, sociais, discursivas, linguísticas), todas dependentes da situação e das finalidades de leitura, algumas delas denominadas, em algumas teorias de leitura, estratégias (cognitivas, metacognitivas).

Desse modo que, com passar do tempo o termo letramento foi sendo moldado e agregado à novas ideias e valores que representem um conceito muito mais amplo e completo de leitura, o qual traduza todo um processo que não se restringe a mera decodificação de símbolos, mas ao desenvolvimento de uma prática sócio, política, histórica e cultural que permita a formação de leitores críticos e protagonistas.

Segundo Kleiman (2005, p. 5), “'Letramento’ é um conceito criado para referir-se aos usos da língua escrita não somente na escola, mas em todo lugar. Porque a escrita está por todos os lados, fazendo parte da paisagem cotidiana." O que nos faz perceber que dentro de determinada cultura há diferentes letramentos associados a diferentes domínios de vida. E, se pensarmos, em tudo que está envolvido numa situação em que se utiliza a língua escrita veremos que as capacidades envolvidas vão muito mais além do que pode ser ensinado na escola. Para a autora, as práticas de letramento presentes no contexto escolar 
são construídas no processo de interação entre professor e aluno, em que o indivíduo identifica o elo entre as práticas de letramento na aula e as necessidades do uso da escrita no cotidiano. (KLEIMAN, 1998). Esse tipo de letramento é denominado letramento acadêmico (Kleiman, 1998) ou letramento escolar (Soares, 1998) caracterizado por requerer formas diferenciadas de oralidade e de escrita, importantes para a escolarização e que emergem das práticas sociais tecnologicamente mais sofisticadas em sociedades escolarizadas (Rojo, 2009).

Nesse sentido Rojo (2009, p. 107) chama atenção para um dos objetivos principais da escola hoje em dia que é "justamente possibilitar que seus alunos possam participar de várias práticas sociais que se utilizem da leitura e da escrita (letramentos) na vida da cidade, de maneira ética, crítica e democrática", levando em consideração os diversos tipos de letramentos.

Assim, nas aulas de qualquer disciplina, os textos, geralmente os do livro didático, não seriam usados como pretexto para introduzir conteúdos, fazer os alunos decorarem palavras sem sentido, com aplicação mecânica, descontextualizadas, mas teriam leituras variadas de textos que circulam nas esferas sociais, pois quanto mais a escola se aproxima das práticas sociais em outras instituições (família, trabalho, igreja), mais o aluno poderá trazer conhecimentos relevantes das práticas que já conhece, e mais fáceis serão as adequações, adaptações e transferências que ele fará para outras situações da vida real, pois o letramento é usado nessas instituições como ação e interação.

De acordo com Kleiman (2005, p. 23),

Um evento de letramento inclui atividades que têm as características de outras atividades da vida social: envolve mais de um participante e os envolvidos têm diferentes saberes, que são mobilizados na medida adequada, no momento necessário, em prol de interesses, intenções e objetivos individuais e de metas comuns.

O que o torna um evento colaborativo, dependendo de outras pessoas para que se torne significativo. Diferentemente da prática tradicional da sala de aula, que envolve a demonstração da capacidade individual de realizar todos os aspectos das tarefas. 
Nessa perspectiva, as práticas pedagógicas precisam almejar a criação de oportunidades de se experimentar a leitura e a escrita de textos significativos que cumpram diferentes funções sociais, e é necessário que elas estejam presentes na sala de aula, na aprendizagem de conteúdos acadêmicos e em todo o ambiente escolar.

Como já dizia Rojo (2009, p. 112),

Por isso se tornam tão importantes hoje as maneiras de incrementar, na escola e fora dela, os letramentos críticos, capazes de lidar com os textos e discursos naturalizados, neutralizados, de maneira a perceber seus valores, suas intenções, suas estratégias, seus efeitos de sentido. Assim, o texto já não pode mais ser visto fora da abrangência dos discursos, das ideologias e das significações, como tanto a escola quanto as teorias se habituaram a fazer.

Em se tratando da Educação de Jovens e Adultos, a concepção limitada de leitura dos/as educadores/as, a partir da lacuna deixada, tanto na educação inicial como continuada, é refletida no ensino-aprendizagem de leitura, nesse caso específico, ou seja, um ensino de leitura padronizado seguindo passos repetitivos de: ler o texto, de preferência em voz alta, responder questionários, estudar gramática e redação, tudo isso acontecendo sem grande variação, durante todas as aulas que seriam destinadas à leitura, que se torna um mecanismo estafante e previsível (SILVA, 1999).

Faz-se necessário que a escola leve em consideração que estes jovens e adultos são portadores de culturas: cultura do meio rural, da periferia, da vila, da origem afro, indígena, de certa religião, etc. Estes jovens e adultos são trabalhadores, pais, mães, esposos, esposas, namorados e namoradas, filhos e filhas. Eles educam, cuidam de si, cuidam de outros, eles têm múltiplos saberes. Eles, principalmente, aprenderam a sobreviver num mundo regido pelo valor da escrita, em que a escolarização vale a possibilidade de obter empregos e ascender socialmente: permite preencher fichas, ler documentos, usar a escrita como forma de perpetuar a memória, de obter informações, de comunicar-se à distância.

Estes jovens e adultos, homens e mulheres, sabem muito do valor social da escrita, muito mais que qualquer pessoa escolarizada. Para nós se tornou tão trivial usar a escrita que, com certeza, não podemos imaginar o que seria viver sem fazer uso dela. No entanto, 
pessoas não-escolarizadas sabem muito bem os usos que são feitos da escrita, sabem para que serve, onde é usada e, provavelmente, o que deve estar escrito nos diversos portadores de texto que encontramos no nosso meio. Isto significa que estas pessoas tem um processo de letramento bastante avançado que deve ser reconhecido. Eles até criam estratégias de leitura de símbolos, sinais, imagens, cores, números, que lhes permite orientar-se no meio urbano e desenvolver suas atividades de trabalho mesmo sem o domínio da leitura e da escrita. Eles também resolvem contas mentalmente, na maioria das vezes sem fazer uso das operações matemáticas formais.

Conforme Soares (1998), na EJA o educando deveria ser visto como sujeito sóciohistórico-cultural, com conhecimentos e experiências acumuladas. Possuindo um tempo próprio de formação, apropriando-se de saberes locais e universais, a partir de uma perspectiva de ressignificação da concepção de mundo e de si mesmo. Tendo em vista a diversidade desses educandos, com situações socialmente diferenciadas, é preciso que a Educação de Jovens e Adultos proporcione seu atendimento por meio de outras formas de socialização dos conhecimentos e culturas, levando-se em conta suas especificidades.

Entendendo que o letramento nos permite continuar aprendendo, precisamos de ferramentas para continuar a aprendizagem, e a leitura é a ferramenta por excelência para isso. Nesse sentido, segundo Kleiman (2005, p. 51), "para formar leitores, o professor, além de ser plenamente letrado, é claro, precisa ter os conhecimentos necessários para agir como um verdadeiro agente social. Ele tem de ser um gestor de recursos e saberes - tanto dos dele como dos seus alunos.” Deve-se levar em consideração que o agente social deve primeiro descobrir se a atividade tem relevância na vida do outro antes de ensinar um novo modo de se relacionar com o texto. Como todo agente social é um agente de letramento, o professor sendo esse agente é promotor das capacidades e recursos de seus alunos e de suas redes comunicativas para que participem das práticas de uso da escrita situadas nas diversas instituições. KLEIMAN (2005)

Para tanto, também deve-se considerar os documentos oficiais que regem a educação brasileira, como os PCN que propõem o desenvolvimento das capacidades de pesquisar, buscar informações e analisá-las, da capacidade de aprender, criar e formular hipóteses 
a respeito das práticas cotidianas ao invés do exercício de memorização e imposição de modelos.

\section{Considerações finais}

Diante da discussão proposta neste artigo, pudemos perceber que a escola pode formar um cidadão flexível, democrático e protagonista, que seja multicultural em sua cultura e poliglota em sua língua. (ROJO, 2009, p. 115)

Cabe, portanto, também à escola potencializar o diálogo multicultural, trazendo para dentro de seus muros não somente a cultura valorizada, dominante, canônica, mas também as culturas locais e populares e a cultura de massa, para torná-las vozes de um diálogo, objetos de estudo e de crítica. Para tal, é preciso que a escola se interesse por e admita as culturas locais de alunos e professores.

Certamente a escola pode inovar e ousar com a intenção de captar a multiplicidade e pluralidade do letramento, acompanhando as novas demandas da sociedade contemporânea e proporcionando ao aluno o desenvolvimento de estratégias de acesso a informação e traçando caminhos que façam sentido para ele. O professor, por sua vez, enquanto agente social pode orientar o trabalho do aluno fornecendo materiais relevantes e modelos de atividades significativas que proporcionem ao aluno sua constituição de sujeito livre, capaz de contribuir para as mudanças sociais.

Assim, cabe à escola inserir novas práticas de letramento relacionadas aos conteúdos acadêmicos e orientar o aluno na construção de textos escritos e orais de forma que ele aprenda a utilizar a linguagem culta e formal (Rojo, 2001). Essas habilidades devem permitir ao aluno compreender e participar das distintas manifestações da cultura e olhar a leitura e a escrita de forma reflexiva e crítica, para que atue seletivamente frente aos meios de comunicação social, pois, para Soares (1998), quando o sujeito é capaz de interpretar, divertir-se, seduzir, sistematizar, confrontar, induzir, documentar, informar, orientar-se, reivindicar e garantir a sua memória, este se abarca do efetivo uso da escrita, garantindolhe uma condição diferenciada na sua relação com o mundo, um estado não necessariamente conquistado por aquele que apenas domina o código. Assim, para que o sujeito 
conquiste seu espaço na sociedade, deve ir além dos conhecimentos das letras, deve ter a possibilidade de uso efetivo de um conhecimento que o possibilite nas formas de expressão e comunicação, em um determinado contexto cultural.

Nesse contexto, o educador de jovens e adultos precisa respeitar as condições culturais dos jovens e dos adultos, realizando um diagnóstico histórico-econômico do grupo junto ao qual irá trabalhar e estabelecer um canal de comunicação entre o saber técnico e o saber popular com uma prática pedagógica que leve em consideração a diversidade sociocultural de seu público, composto por populações do campo, em privação de liberdade, com necessidades educativas especiais, indígenas, remanescentes de quilombos, entre outros, que demandam uma educação que considere o tempo, os espaços e a sua cultura.

Para tanto, a escola também deve considerar os documentos oficiais que regem a educação brasileira, como os PCN que propõem o desenvolvimento das capacidades de pesquisar, buscar informações e analisá-las, da capacidade de aprender, criar e formular hipóteses a respeito das práticas cotidianas ao invés do exercício de memorização e imposição de modelos.

É preciso ampliar e democratizar tanto os eventos e as práticas de letramento dentro do ambiente escolar como o universo e a natureza dos textos que nela circulam. Nesse sentido, Rojo (2009, p. 106-107), ressalta que

Essas mudanças fazem ver a escola como um universo onde convivem letramentos múltiplos e muito diferenciados, cotidianos, institucionais, valorizados e não valorizados, locais, globais e universais, vernaculares e autônomos, sempre em contato e em conflito, sendo alguns rejeitados ou ignorados e apagados e outros constantemente enfatizados.

Além disso, Kleiman (1998) afirma que as práticas de letramento, presentes no contexto escolar, são construídas no processo de interação entre professor e aluno. Nessa interação, o aluno deve identificar o elo entre os eventos de letramento na aula e as necessidades dos usos da escrita no cotidiano, tornando o letramento, no contexto escolar, um processo contínuo dos usos sociais e culturais da leitura e da escrita. Defendemos aqui a 
necessidade de aliar o trabalho com a linguagem, especificamente as práticas de leitura e escrita, à vida social e política na qual o educando está inserido.

Portanto, partindo da premissa de que as pessoas são competentes e possuem conhecimento. A escola pode e deve usar esse conhecimento, como ponto de partida para construir outros no contexto de ensino-aprendizagem escolar, que tornarão as ações pedagógicas positivas e, certamente, mais significativas.

Ademais, cabe aos professores trabalhar com esferas sociais e culturais e com os gêneros que nelas emergem e circulam, servindo de ponte para a construção de conhecimento e protagonismo por parte de nossos alunos, fazendo com que eles percebam seu poder de produção e criticidade.

\title{
(RE) THINKING READING IN YOUTH AND ADULT EDUCATION: FOR A LETTERED PRACTICE
}

\begin{abstract}
This paper aims to discuss the reading process in Youth and Adult Education (postliteracy) seeking to understand what it is to read, what the focus of this practice and its relevance to the audience of Youth and Adult Education (EJA). We reflected on the need to reframe the concept of reading in order to broaden our conceptions and (re) think about our daily practices in the classroom, enabling the training of readers for a literate practice that makes them able to interact using language in different ways in different actions and in different groups, whether social, cultural etc. We made a brief history of the EJA supporting us in the studies of Arroyo (2005); we take as a basis the concepts of reading brought by Arroyo (2005), Kleiman (1999, 2013), Silva (1999, 2002), Soares (2003) and by the National Curriculum Parameters (PCN) (1998); and finally, we rely on Kleiman (1998, 2005), Silva 1999), Soares (1998), and Rojo (2009) to deal with literacy. Keeping as proposal to (re) think about reading in Youth and Adult Education classes, we realize that the process of training readers in this teaching modality will be more pleasurable and meaningful and, consequently, will obtain better results if the socio-historical contexts which these subjects are inserted are taken into account.
\end{abstract}

KEYWORDS: EJA; Reading; Literacy.

\section{REFERÊNCIAS}

ARROYO, M. A educação de jovens e adultos em tempos de exclusão. In: SECAD; RAAAB. Construção coletiva: contribuições à educação de jovens e adultos. Brasília: Unesco, MEC, RAAAB, 2005.

BRASIL. Secretaria de Educação Fundamental. Parâmetros Curriculares Nacionais: terceiro e 
quarto ciclos do ensino fundamental: língua portuguesa/Secretaria de Educação Fundamental.

Brasília: MEC/SEF, 1998.

KLEIMAN, A. B. Ação e mudança na sala de aula: uma pesquisa sobre letramento e interação. Em R. Rojo (Org.) Alfabetização e letramento. Campinas: Mercado de Letras, 1998.

. (Org.). Os significados do letramento: uma nova perspectiva sobre a prática social da escrita. Campinas, SP: Mercado de Letras, 1999.

. Por que "ensinar" o letramento? Não basta ensinar a ler e a escrever? Coleção Linguagem e letramento em foco. Cifiel/IEL/Unicamp, 2005.

Texto e leitor: Aspectos cognitivos da leitura. 15. ed., Campinas, SP - Pontes Editores, 2013.

ROJO, R., Letramento escolar, oralidade e escrita em sala de aula: diferentes modalidades ou gêneros do discurso? Em I. Signorini (Org.) Investigando a relação oral/ escrito e as teorias do letramento (pp. 51-74). Campinas: Mercado de Letras, 2001.

. Letramentos múltiplos, escola e inclusão social. São Paulo: Parábola, 2009.

SILVA, E. T. da, De olhos abertos: reflexões sobre o desenvolvimento da leitura no Brasil. 2. ed. São Paulo: Ática, 1999.

. O Ato de Ler: fundamentos psicológicos para uma nova pedagogia da leitura. 9. ed., São Paulo: Cortez, 2002.

SOARES, M. B. Letramento: um tema em três gêneros. Belo Horizonte: Autêntica, 1998. Disponível em: https://sites.google.com/site/estudosdeletramento/. Acesso em: 20 nov. 2019.

. Letramento e escolarização. In: RIBEIRO, Vera Masagão (Org.). Letramento no Brasil: reflexões a partir do INAF 2001. São Paulo: Global, 2003.

Recebido em: 15/09/2020.

Aprovado em: 22/10/2020. 